\title{
Influencia de la radio con un enfoque educomunicativo para la formación ciudadana
}

\section{Influence of the radio with an educommunicative approach for citizen training}

Betty Isabel Rodas

Angelica Celleri Aveiga

Universidad Politécnica Salesiana, Ecuador

Autor para correspondencia: brodas@ups.edu.ec

Fecha de recepción: 02 de Agosto de 2017 - Fecha de aceptación: 10 de Agosto de 2017

Resumen: La Educomunicación constituye un paradigma que posibilita la formación ciudadana, desde la recepción hasta el análisis crítico de los mensajes mediáticos, se trata de un conjunto de acciones que influyen en la adquisición de aprendizajes informales directa o indirectamente. Desde esta perspectiva se toma como eje de análisis a la radio y el componente educomunicativo implícito, considerando como premisa principal que a lo largo de su historia ha estado está ligada a procesos de desarrollo (en el plano educativo, cultural y participativo) siendo el medio propicio para formar en ciudadanía. De acuerdo a estos parámetros el propósito de este artículo es determinar mediante una metodología cualitativa, la influencia de la radio con un enfoque educomunicativo para la formación ciudadanía con libertad de expresión, liderazgo y empoderamiento capaz de recuperar la palabra pública para transmitir a las comunidades y pueblos ecuatorianos los valores sociales, que permita una convivencia armoniosa. El resultado sería evidenciar que la radio necesita recuperar espacios y la palabra pública para que mediante géneros y formatos creativos desprovistos de la arrogancia de los medios comerciales masivos (supeditados a ratings) favorezcan a la formación ciudadana y en consecuencia la democratización de la palabra.

Palabras claves: educomunicación; radio; ciudadanía; democratización; participación

\begin{abstract}
Abstrac: Educommunication is a paradigm that enables citizen formation, from reception to critical analysis of media messages, is a set of actions that influence the acquisition of informal learning directly or indirectly. From this perspective, the radio and the implicit Educommunicational component are taken as the axis of this analysis, considering as the main premise that throughout its history has been linked to development processes (educational, cultural and participatory) being the ideal medium to form in citizenship. According to these parameters, the purpose of this article is to determine, through a qualitative methodology, the influence of the radio with an educomunicative approach for citizenship formation with freedom of expression, leadership and empowerment, capable of recovering the public word to transmit to the communities and Ecuadorian people social values, guiding them towards a behavior that allows a harmonious coexistence. Therefore, the result would be to show that the radio needs to recover spaces and recover the public word, so throughout creative formats and genres devoid the arrogance of the mass media (subject to ratings), favor the citizen formation and, consequently, the democratization of word.
\end{abstract}

Key words: educommunication; radio; citizenship; democratization; participation 


\section{Introducción}

La educomunicación terminológicamente implica la conjunción de la educación y la comunicación, pero además por su interdisciplinariedad, accionar y recorrido en América Latina, con una trayectoria de más de 40 años, ha estado vinculada a procesos de cambio de intervención social, actualmente ante al contenido de mensajes mediáticos de los medios de comunicación, especialmente de los masivos y las nuevas tecnologías se la relaciona con la recepción calificada de mensajes mediáticos, en este contexto la educomunicación alcanza una mayor presencia y representatividad en las diferentes instancias sociales, como un paradigma que orienta un conjunto de acciones en el plano de la recepción, educación y participación.

Ahora bien, con respecto a la radio y a la educomunicación se ha teorizado de forma aislada, desperdiciando la riqueza que podría generar su encuentro, desde un replanteo de las formas de aprender dentro y fuera del aula con mediación de la radio. Por tanto es necesario redimensionar el valor de la radio y su poder coloquial como un medio que sigue vigente y asume el desafío de influir positivamente en la ciudadanía, favoreciendo al desarrollo de una mayor interlocución mediante un lenguaje sencillo que posibilite procesos dialógicos de comunicación; estas características inciden en la democratización de la palabra, en la participación y en la formación ciudadana.

En consecuencia la correspondencia entre educomunicación y radio parte del hecho que esta última posee desde su origen un ámbito de servicio ciudadano y de defensa de los derechos, en el que reside su verdadera razón de ser, como un medio que además de informar puede empoderar a la ciudadanía mediante contenidos que culturicen y formen con criticidad. Sin embargo en el camino la radio, ha perdido su esencia por afanes mercantilistas y hedonistas, es preciso recuperar las partituras iniciales y se reivindiqué la naturaleza de la radio.

Por ello el alcance de la investigación conlleva a un cuestionamiento del papel de la radio y la factibilidad que mediante un enfoque educomunicativo se fomente al pensamiento crítico y la participación, lo cual es parte indispensable en la formación ciudadana. La Ley Orgánica de Comunicación tipifica en su artículo 71, que la comunicación social es un servicio público que deberá ser prestado con responsabilidad y calidad. En ese mismo artículo en el inciso 10 establece la propensión a la educomunicación, lo cual es sustento y hace que este artículo tenga mayor proyección ante el panorama de cambios en el Ecuador a partir de la promulgación de nuevas leyes y reglamentos.

Se trata de cambios para lograr el Buen Vivir y la concepción de un nuevo ciudadano que no se construye en papeles, debe tangibilizar en la realidad, con un compromiso asumido desde el protagonismo, la acción y la participación que exige sus derechos y se hace escuchar, como un sujeto de comunicación supera el plano de la recepción, conforme al modelo propuesto por Kaplùn $^{1}$, se convierten en EMIREC, y que en una sociedad de la Información y de la

\footnotetext{
${ }^{1}$ Mario Kaplùn en su obra Hacia una Pedagogía de la Comunicación establece Modelos de Comunicación exógenos basado en los Contenidos corresponde a una educación tradicional y otra fundamentada en los efectos la intención es que el estudiante haga. El otro modelo Endógeno basado en el proceso.
} 
comunicación se puede identificar como Prosumidores ${ }^{2}$, con estos antecedente se establece la importancia del artículo, que analiza la influencia de la radio con un enfoque educomunicativo en la formación ciudadana, para tal efecto es el propósito del presente artículo identificar a la educomunicación como un paradigma y su encuentro con la radio como un medio de participación. Además de determinar principios de formación ciudadana, mediante el empleo de géneros y formatos creativos.

\section{Metodología}

La metodología cualitativa posibilita la descripción del objeto de estudio mediante un análisis documental sobre los hechos y situaciones que caracterizan a la radio con un enfoque educomunicativo y que contribuyen en la formación ciudadana. De esta manera la recopilación de datos y el estado del arte levantado sobre el tema se contrasta con las entrevistas desarrolladas.

Se recurre a la metodología cualitativa por cuanto admite contextualización y análisis del objeto de estudio, según Rodríguez, Gil \& García (1996) la investigación cualitativa interpreta los fenómenos de acuerdo con los significados que tienen para las personas involucradas, por lo cual se emplea a una gran variedad de materiales y técnicas como entrevistas, experiencia personal, historias de vida, observaciones, textos históricos, que logran describir rutinas y situaciones diversas en la vida de las personas.

La investigación cualitativa es sobretodo empleada en situaciones donde lo que se quiere saber qué piensa sobre una situación concreta, cómo vive o experimenta cambios de hábitos y costumbres, es decir cuando se requiere de información cualitativa sobre vivencias, percepciones, sentimientos y emociones. (Balcàzar Nava, Gonzàlez Arratia Lòpez-Fuentes, Gurrola Peña, \& Moysèn Chimal, 2013), la metodología cualitativa es valiosa para establecer lineamientos y/o principios de formación ciudadana a través de la radio.

Este medio que tiene una trascendencia incuestionable, por su cobertura geográfica, audiencia, y ha marcado durante el siglo XX, una época histórica en lo político, noticioso y musical es idóneo para el desarrollo social.

Desde finales 1929, cuando apareció la primera emisora, la radiodifusión creció hasta tener hoy 1.205 frecuencias distribuidas en Onda Corta (21), Amplitud Modulada (271) y Frecuencia Modulada (913), siendo el $97 \%$ privadas. Si se compara con su número de habitantes, el país tiene un exceso de estaciones en relación otros países de similar tamaño. (Jordàn \& Panchana, 2015)

La radio es uno de los medios de mayor consumo al considerar audiencias y cobertura su incidencia e importancia es notable de este modo las radios de antena tienen en un 33,62\% transmiten su programación también por Internet. El 57,72 \% de las radioemisoras tiene programación durante las 24 horas del día. En estudios realizados de forma reciente al menos el

\footnotetext{
${ }^{2}$ Prosumidor, para García Canclini, implica que la flexibilidad de la comunicación, el individuo es productor y consumidor.
} 
87,6 \% de los hogares en Ecuador posee un radio receptor. (Gehrke, Lizarazo, Noboa, Olmos, \& Pieper, 2016).

En el Ecuador la radio es el segundo medio más consumido, con el advenimiento de los medios públicos también se ha configurado una radio pública que enriquece contenidos para la formación de una conciencia social y ciudadana, sin embargo se puntualiza que de acuerdo a una investigación del Centro Internacional de Estudios Superiores de Comunicación para América Latina (Ciespal) sobre la percepción de los medios públicos en Ecuador, solo un 13,75 $\%$ de les encuestados en Quito y Guayaquil dice escuchar radio pública todo los días, contra un $43 \%$ que no la escucha nunca. (p. 20).

De acuerdo lo expuesto la radio es un medio identificador y positivo, que fomenta la participación de las audiencias mediante un contacto constante, de ahí que desde el componente educomunicativo, lograr una recepción calificada del mensaje, conforme a las leyes, reglamentos enmarcados en la Ley Orgánica de Comunicación (LOC) políticas públicas de comunicación y el Plan Nacional del Buen Vivir, es una tarea plausible. La radio, no solo debe entretener con música y concursos, si conjugamos todo esto se puede educar a las personas de alguna manera, con segmentos educativos donde puedan llegar a formar su propia opinión acerca de lo que está ocurriendo el momento.

En otro orden de ideas cabe señalar que las emisoras en AM, han estado vinculadas tradicionalmente con la opinión y la información siendo un elemento importante para la formación ciudadana, se podría establecer además que el AM, por su cobertura y contenidos está dirigido a un público adulto, y ha dado prioridad al acontecer noticioso y a contenidos culturales.

En tanto que las emisoras en FM, presentan una mayor acogida en la población joven y joven adulta, emisoras tales como Radio Centro, América Guayaquil, Tropicana, Forever gozan de mayor índice de sintonía en aspectos tales como educativo, cultural y de opinión según datos proporcionados por la empresa Mercados \& Proyectos ${ }^{3}$ a enero del 2017 ; a pesar de aquello una característica en las parrillas de programación es el componente musical, se evidencia que el contenido vinculado con la formación ciudadana está supeditado a las capsulas interculturales y a la franja de la hora educativa promovida por la SECOM y el Ministerio de educación.

Los contenidos interculturales y la franja educativa constituyen una exigencia que emana de Ley Orgánica de Comunicación. Así la franja educativa da cumplimiento al artículo 74, numeral 3 establece que los medios de comunicación audiovisuales de señal abierta tendrán la obligación de prestar gratuitamente servicios sociales de información de interés general.

\footnotetext{
${ }^{3}$ Mercados y Proyectos, empresa de Investigación de Mercados, estudio realizado a enero 2017: rating radios AM y FM a nivel educativo, cultural, opinión
} 


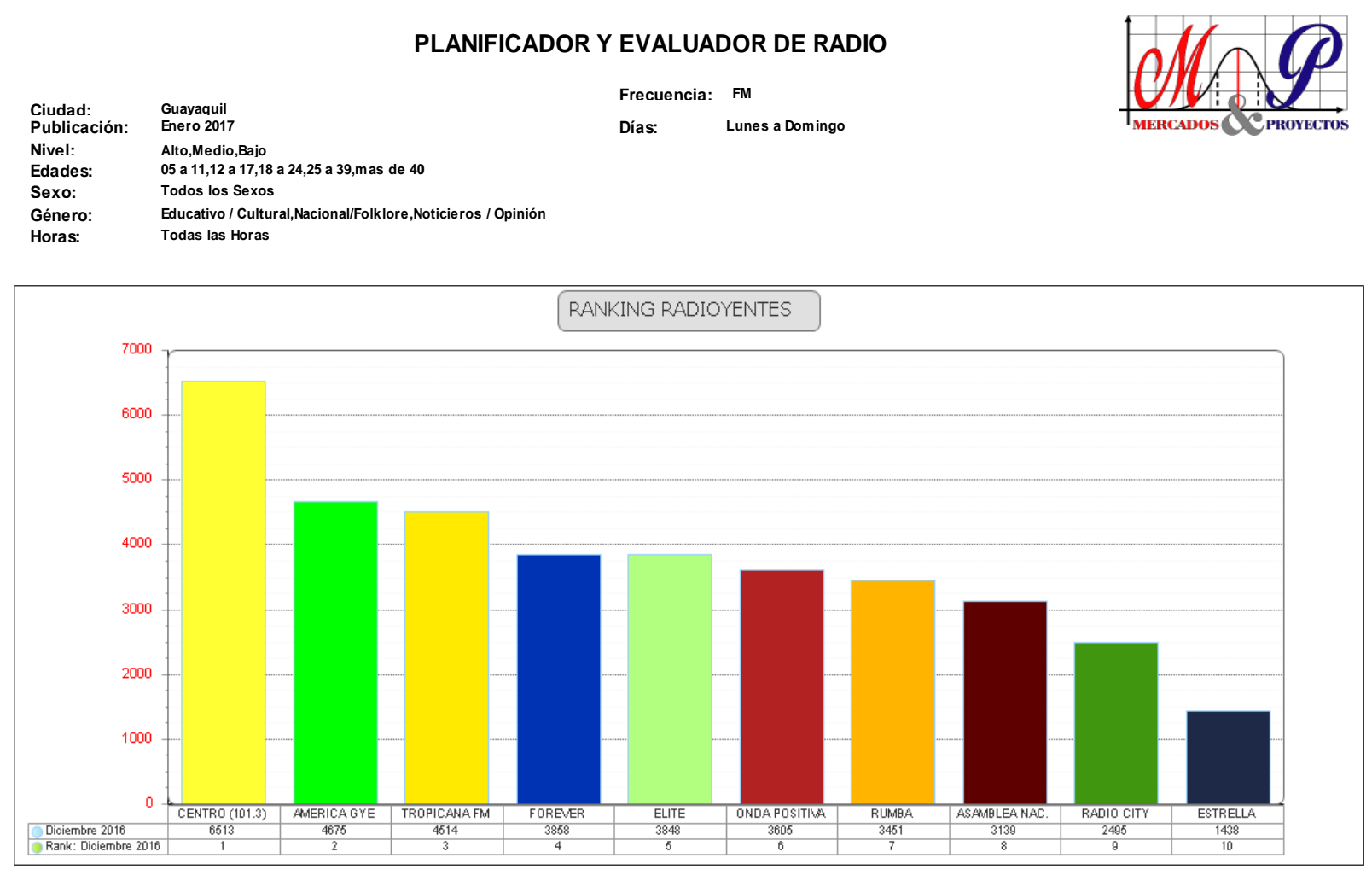

Enero 2017 rating radios FM a nivel educativo, cultural o de opinión. Fuente Mercados \& Proyectos

La norma también señala que se debe destinar una hora diaria -no acumulable- para programas oficiales de tele-educación, cultura, salubridad y derechos elaborados por los ministerios o secretarías con competencia en estas materias. Radio educa como una propuesta educomunicativa aborda temas como problemáticas sociales y desarrollo infantil, se transmite en AM y FM a discreción de cada emisora.

Estas acciones favorecen y fomentan la ciudadanía, pero como ya se ha manifestado dan cumplimiento a leyes y son obligaciones para el medio, más no una iniciativa del mismo. No obstante mediante entrevistas realizadas a diferentes locutores entienden y reconocen en la radio a un medio formulado para el entretenimiento del público, considerada también como un negocio, reconocen también en la radio un medio que puede educar una de las formas más recurrentes ((educar no es igual a informar)) es a través de la información, a pesar de que su principal finalidad es entretener, divertir, existe una responsabilidad implícita que es la de educar, "La gente piensa que cuando se dice educativa es una radio donde va a ser aburrida, donde vas a tener que recibir mucha información, donde te vas a dormir, es el concepto que tiene la gente cuando tú le dices educación, uy no, no y sale corriendo". No debe ser de esa forma, debe más bien, en cada enfoque de los programas agregarle la parte educativa, pero con un estilo que llame la atención del oyente. (Morocho , 2016)

Lograr desvincular lo educativo de lo aburrido, lo cultural de lo educativo o el ámbito información del ámbito educación es fundamental para potenciar a la radio como un medio de formación ciudadana, cuyo enfoque educomunicativo no subyace solo en la parte educativa sino en un conjunto de factores que a criterio de otros locutores de gran trayectoria, reconocen en la 
radio con ese componente educomunicativo como el mensaje a difundir debe basarse en una comunicación buena, " nosotros podemos comunicarnos a través de la palabra, de la expresión corporal (...), a través de gestos (...), podemos educar a través de la comunicación pero cuando eres asertivo, cuando sabes cómo dirigirte al público que vas a tratar”. (Carrillo, 2016)

Una radio que se oriente a la formación ciudadana debe ser participativa y para considerarla participativa tiene que ser inclusiva, a criterio de Julio César Ramón (2016), locutor y presentador de Radio Morena, "incluir a las personas que no tienen un fácil acceso a la radio, sobre todo con personas con discapacidades, personas con otra inclinación sexual, incluso hasta personas que son de diversos estratos sociales" sostiene que la participación permite a los oyentes tener de actividad dentro de sus programaciones, una radio participativa seria la que escucha a sus oyentes, cuando el oyente hace una crítica, algún comentario y rectifica sus comentarios .

La radio es un medio democrático nace siendo educativo, es eminentemente participativo por lo cual lo inclusivo es parte consustancial de su accionar, según Villamayor \& Lamas (1998), la temática de la ciudadanía y de la democracia se entrelaza con la comunicación, en tanto y en cuanto el sistema de medios se constituye en un espacio para el debate. De esta manera la radio como un medio audiovisual constituye en un espacio de participación, de denuncia, donde la realidad se legitima, pero al mismo tiempo en el lugar de las manifestaciones culturales, sociales y hasta religiosas.

Desde la perspectiva de Buendía \&Pino (2008) la radio tiene una relación ineludible con la participación ciudadana en la sociedad contemporánea, cada vez más, se evidencia cómo aparecen nuevas formas de interpretar y asumir la ciudadanía; por tanto la radio, como vehículo, genera un impacto comunicativo para favorecer a una colectividad critica, incluyente y democrática.

\section{Hacia una conceptualización de la Educomunicación en un contexto mediático}

La conjunción de la comunicación y educación de forma tradicional se la consideraba solo en el ámbito de la relación docente- estudiante, sin embargo, trasciende el plano relacional, constituyendo dos aristas de una misma realidad, ante la incuestionable presencia de los mensajes mediáticos y la influencia de los medios en el aula. Es importante destacar que la educomunicación denominada también como alfabetización mediática, educación en materia de comunicación, alfabetización digital, media literacy ${ }^{4}$ entre otros nombres que identifican su campo disciplinar, se la contextualiza en el marco de dos ejes claves la mediación y la mediatización, que siendo diferentes están estrechamente vinculados, así el primero influye en la forma, contenido y recepción del mensaje y el segundo en el impacto que los medios de comunicación tienen en la transformación de la cultura y la sociedad moderna. (Hjarvard, 2016)

\footnotetext{
${ }^{4}$ El concepto nació en la escuela anglosajona bajo la denominación de Media Literacy, refiriéndose a la formación de individuos mediáticamente alfabetizados a través de la educación en medios (Media Education). Actualmente la UNESCO reconoce la designación de Media and Information Literacy, y se expresan dos nombres nuevos en Estados Unidos: New Literacy y Media Literacy Education.
} 
La educomunicación conjuga la tecnología, la vertiente informacional de los medios y la mediación que implica una sociedad con diferentes consumos culturales, es evidente que las sociedades cambian y según Canclini (2001) se producen hibridaciones culturales que el autor define como: "procesos socioculturales en los que las estructuras o prácticas discretas, que existían en forma esperada, se combinan para generar nuevas estructuras, objetos y prácticas"(p.14), de esta forma los medios contribuyen en una hibridación cultural de forma discreta y gradual, posicionan en la mente de las audiencias otras prácticas culturales que incluso influyen en la pérdida de identidad y de valores ciudadanos. Favorece para que los individuos dirijan su mirada y participen de los principales problemas sociales, en defensa de los derechos humanos, el medio ambiente y la libertad de expresión.

Junto con Gozàlvez \& Contreras Pulido (2014) se afirma que la "educomunicación no se entiende de modo completo sin su finalidad cívica, es decir, sin su trasfondo ético, social y democrático relacionado con el empoderamiento de la ciudadanía en cuestiones mediáticas"(p.130), la radio con esta finalidad contribuye a la toma de decisiones, la autonomía y el desarrollo de aspectos tan importantes como la inclusión y la interculturalidad todo esto se visibiliza como acciones afirmativas de participación ciudadana.

\section{La Educomunicación como un paradigma}

La Educomunicación es considerada un nuevo paradigma porque no se opone al consumo mediático y, al contrario, reconoce la presencia e influencia de los medios en la vida cotidiana e incluso pretende educar junto a ellos, al tomarlos como fuente de material de interés para el aula.

Los medios anglosajones impusieron su modelo educomunicativo sin tomar en consideración el modelo latinoamericano, que logra fusionar la educación con la comunicación, sobre la base y sustento de teorías comunicativas y modelos educativos, que contemplan a su vez ideas como la igualdad y la libertad. (Castro Lara, 2011)

Según Pérez (2010) en la revista Tendencias XXI, manifiesta que la educomunicación tiene que ser estratégica porque no es solo educar para la comunicación sino que hay que buscar las estrategias adecuadas para lograrlo, y los educandos deben aprovechar las potencialidades que les brinda la educomunicación para que de esta manera puedan entender a los demás y ellos vayan formándose y puedan convertirse en seres transformadores de este mundo.

La educomunicaciòn más allá de un paradigma es una forma de acción y mediación entre la tecnología, los medios y su influencia en el aula, para Agustín García Matilla (2001) incide en la minimización de los riesgos de manipulación:

La educomunicación aspira a dotar a toda persona de las competencias expresivas imprescindibles para su normal desenvolvimiento comunicativo y para el desarrollo de su creatividad. Asimismo, ofrece los instrumentos para: comprender la producción social de comunicación, saber valorar cómo funcionan las estructuras de poder, cuáles son las técnicas y los elementos expresivos que los medios manejan y poder apreciar los mensajes con suficiente distanciamiento crítico, minimizando los riesgos de manipulación. (p.1) 
En tanto es necesario señalar que para José Ignacio Aguded (2012) la educomunicación presenta dos niveles de justificación: el nivel de consumo (omnipresencia) el mismo que denota la saturación de los medios y los tiempos dedicados, es decir un excesivo consumo de medios. Los niveles de penetración (omnipotencia) refieren a la importancia ideológica de los medios y su influencia como empresas de concienciación.

\section{La Educomunicación y la recepción crítica de los mensajes}

\section{Mass mediación y Audienciación}

Una característica distintiva de la actual sociedad es corresponder a distintas audiencias, medios y tecnologías de información. La Audienciación es la creciente segmentación social provocada por la extensa cobertura de los medios y las TICS y su vinculación con los sujetos sociales. A diferencia de segmentaciones de clase, género, raza, cultura, geográficas o políticas, esta se origina en la interacción diversificada entre los medios y la sociedad, particularizada en la interacción entre las sociedades, la información y el conocimiento. (Gómez, 2010).

Existe una creciente y cada vez más estrecha relación entre los individuos sus comportamientos en la sociedad y los modelos de conducta asumidos con la interacción con los medios y tecnologías, desde este punto de vista la radio se aliena a los consumos culturales provenientes de otros medios de comunicación.

Esta vorágine de consumos culturales se debe principalmente porque además de vivir en una sociedad del conocimiento y la información estamos viviendo en una sociedad de la educación, junto con Orozco (2004) se considera que la escuela dejó de ser la institución educativa por excelencia y que la educación se realiza desde las mismas relaciones sociales, con referentes cognoscitivos procedentes no sólo de una fuente sino de muchas, en especial aquellas relacionadas con las tecnologías y los medios de comunicación. Por su parte Navarra \& PérezLatre (2004) afirman que los medios tienen una influencia social:

Los medios de comunicación son simplemente cauce de determinados mensajes, aunque en ocasiones se trate de un cauce de notable influencia social y poder de persuasión. Sus contenidos tienen considerable valor para la mejora de la ciudadanía y la transparencia de las sociedades democráticas”. (p.29)

\section{Diversos enfoques en el quehacer educomunicativo}

\section{La interculturalidad}

La interculturalidad es construir caminos que permitan una relación armoniosa para garantizar la diversidad, esta debe tangibilizar en diferentes espacios y actores sociales por este motivo la educomunicación tiene implícito un componente intercultural contemplando el respeto y la no discriminación desde la perspectiva de la educomunicación los contenidos de los diversos programas específicamente en el caso de la radio debe promover un rol crítico, permitiendo construir espacios de encuentro, diálogo y asociación entre seres y saberes reflejándose en la formación de ciudadanos con autonomía e identidad intercultural.

\section{Lo comunitario}


Los medios comunitarios permiten la construcción de ciudadanía, es así como la radio es un medio que contribuye en el proceso de comunicación intercultural y comunitario, la Ley Orgánica de Comunicación en el artículo 36 determina el derecho a la comunicación intercultural y plurinacional, paralelo a esto las políticas públicas favorecen a un mayor desarrollo de medios comunitarias (redistribución de frecuencias ) todo esto con el fin de lograr una mayor justicia social y mejorar las condiciones de vida. Lo fundamental del aspecto comunitario es que abre espacios en la sociedad, y permiten una mayor participación del público, siendo medios accesibles orientados al servicio. Según el portal de la UNESCO (2009) señala: "en la actualidad la radiodifusión es la forma de comunicación comunitaria más corriente en el mundo en desarrollo, ya que su producción y acceso son baratos, tienen un gran alcance y no excluyen a los analfabetos." Se agrega en líneas posteriores que la radio comunitaria se define más por su misión que por su magnitud o ubicación. Se propone educar y entretener, informar y divertir lo cual es positivo tomando en consideración que se ocupa especialmente de aquellos sectores desfavorecidos que no han sido tomados en cuenta o han sido escasamente representados o marginados.

\section{La participación ciudadana.}

La formación ciudadana es un proceso que forma parte de la socialización del individuo, con el propósito de educarlo en valores sociales como la responsabilidad y la cooperación solidaria, identificándose plenamente con su comunidad y el respeto a la convivencia mutua.

José Manuel Pérez (2005) afirma en su artículo Hacia un nuevo concepto de educación en medios que "la nueva educación en medios, tiene, por tanto, que cambiar su enfoque y potenciar la pedagogía de la acción-comunicativa y de la participación”. (p.22) de esta manera formar ciudadanos responsables y participativos, con capacidad de elaborar una crítica y resolver los problemas que se presentan en el día a día.

Históricamente los medios de comunicación se han adaptado a las nuevas formas de transmitir información y metodologías de aprendizaje. La mayoría ha elaborado algún artículo, reportaje o investigación referente a la formación ciudadana, no porque sea un tema de moda, sino por la necesidad de fomentar, mantener y fortalecer los valores necesarios para una convivencia saludable, como el respeto, el compañerismo y la solidaridad. De este modo se consigue la democratización de la comunicación es una cuestión de justicia social, enmarcada en el derecho humano a la información y la comunicación, siendo consustancial a la vida democrática de la sociedad, cuya vitalidad depende de una ciudadanía debidamente informada y deliberante para participar y corresponsabilizarse en la toma de decisiones de los asuntos públicos.

\section{El vínculo narrativo y sonoro entre radio y Educomunicación}

\section{La oralidad de la radio}

La radio sufre la injusticia de que la gente olvidara el gran papel que desempeñó en la transformación del siglo XX y que minimice su función en la cultura popular del siglo XXI. La radio emplea la oralidad y es su principal herramienta, las palabras tienen un poderoso significado. El lenguaje radial es fugaz y su existencia efímera, no es posible detener el sonido. Cuando el locutor transmite su voz la oralidad radial presenta al instante una variedad de 
intercambios: elogios o insultos, debates o discursos, discrepancias o coincidencias, explicaciones y argumentos sobre distintas temáticas con el objetivo de convencer a su audiencia.

"El sonido sin imagen seguirá siendo indispensable para tener todas las mañanas, al escuchar las noticias, el derecho de interpretar por nosotros mismos los acontecimientos del mundo". (UNESCO, 1997)

\section{Géneros y formatos que contribuye a un enfoque educomunicativo}

Los géneros radiales organizan los distintos tipos de contenido que ofrecen las emisoras, clasificándolos en informativos (boletines, entrevistas, editoriales, reportajes, etc.), musicales, dramáticos/ficción, deportivos, culturales, de entretenimiento y de participación (interactuando con llamadas de los oyentes). Generalmente los programas combinan distintos géneros, utilizando el magazine como formato preferido debido a su versatilidad para mezclarlos.

Aunque algunos parezcan más serios que otros, la mayoría pueden contribuir de mayor o menor manera a la radiocomunicación. El informativo ocupa el primer lugar, ya que puede aprovechar una noticia relevante para la comunidad para dar una crónica, opinión o comentario que guie e instruya al oyente. Por ejemplo si ocurre un accidente automovilístico se pueden explicar los peligros del exceso de velocidad o no respetar las normas de tránsito, o si se da una noticia sobre futuras elecciones de dignatarios se pueden dar indicaciones sobre cómo, dónde y que se necesita para realizar el sufragio.

El género cultural es ideal para conocer la historia y profundizar el conocimiento de las diferentes etnias que habitan el Ecuador, las tradiciones ancestrales de sus pueblos amazónicos, las riquezas de la cultura indígena y la afroamericana. De acuerdo a la CIA World Factbook (2016) el país posee una población muy diversa, con el 65\% son mestizos (mezcla de indígenas con caucásicos), $25 \%$ de indígenas, $10 \%$ de caucásicos y $7 \%$ de afro descendientes. Otro género que puede servir de apoyo en este ámbito es el dramático o de ficción. Hasta los programas deportivos pueden enfocar su masiva audiencia hacia temas de relevancia ciudadana, como el respeto mutuo y la no violencia entre hinchadas de equipos rivales, promover la buena salud física y mental a través del ejercicio y el cuidado corporal, así como enseñar las normas de buen comportamiento en espacios públicos y lugares de concentración masivos.

El mismo principio se puede aplicar con los programas de entretenimiento, que pueden reproducir sketches o jingles formativo y cultural, todo depende de la chispa e imaginación del productor radial y sobre todo el empeño de la estación en que su contenido y programas contribuyan a la formación ciudadana a través de la educomunicación.

\section{Concepción de un modelo radio con enfoque educomunicativo.}

Una radio con enfoque educomunicativo debe unificar la variedad de géneros y formatos que existen y amalgamarlos dentro de sus investigaciones y producción de contenidos, basándose en una comunicación popular con perspectiva territorial, que tome los problemas y el contexto del ámbito local, aprovechando las ventajas de la radio, como su masividad, bajo costo, largo alcance, portabilidad e instantaneidad. 
La radio, como medio oral, directo y al alcance de todos, que entretiene, informa, educa e influye, constituye la fuente propicia para educar y formar al sus oyentes, constituyéndose en el mejor medio educativo por el impacto del sonido como fuente estimuladora de la imaginación, fomentando la escucha y la capacitad para la expresión oral, promoviendo y defendiendo los intereses de la sociedad en la que se desarrolla.

Principios educomunicativo para la formación ciudadana mediante el medio radiofónico.

Entre los medios de comunicación masivos que existen en la actualidad, la radio es idónea para la formación ciudadana. Andrés Geerts \& Víctor Van Oeyen (2001) señalan en su libro La radio Popular Frente al Nuevo Siglo: estudio de vigencia e incidencia, lo siguiente:

(...) Las radios ofrecen programas ((Sin organización especial)), pero que, por sus contenidos y enfoques, provocan en el oyente la adquisición de conocimientos, aptitudes y actitudes. Se toma como punto de partida que los sujetos, enfrentados a esa programación radiofónica, tengan su propia capacidad para transformar lo escuchado y darle utilidad mediante la construcción de un significado de acuerdo al contexto. (p.32)

Con el fin de que la radio sea ese verdadero instrumento mediador para la formación ciudadana es necesario solo tres principios fundamentales:

1. Los contenidos de programación deben nacer desde los intereses ciudadanos y no desde los ratings.

2. Recuperar la palabra pública y fomentar la democratización implica repensar los géneros y formatos radiofónicos para que exista una verdadera participación, más allá de llamadas telefónicas o uso de redes sociales.

3. La educomunicación es un eje transversal, para la producción radial: realizadores y locutores deben valorar este componente para que tenga ese aspecto e intencionalidad educativa, cultural, intercultural o comunitaria.

\section{Conclusiones}

Pese al vertiginoso auge de la tecnología la radio ha logrado adaptarse continuamente para seguir vigente como un poderoso medio masivo de influencia ciudadana. La radio comercial no tiene ninguna intención de enseñar o instruir, simplemente busca entretener al oyente sin embargo no debe perder su esencia y debe ajustarse a un nuevo marco legal que lo exige. La Educomunicación es fundamental para formar ciudadanos con sentido crítico, fomenta el análisis y es una forma de contrarrestar la manipulación mediática. Lamentablemente el mercantilismo radial ha mermado su vínculo con la Educomunicación, perdiendo su enfoque al servicio de la ciudadanía.

Los programas radiofónicos en general deben repensar su accionar y fomentar la participación, no es necesario hacer un programa educativo basta con utilizar un lenguaje coloquial, claro y sencillo. Existen géneros y formatos radiofónicos que logran ese cometido, pero actualmente han sido olvidados, el radioteatro es uno de ellos que logra con su creatividad y chispa despertar conciencias y sobretodo el sentido crítico. Al emplear la radio como un instrumento de formación ciudadana es necesario reconocer que la educomunicación es una herramienta, un medio no un fin y que hacer radio con un enfoque educomunicativo no se trata solo de hacer programas educativos, se trata de que los contenidos de programación deben nacer 
desde los intereses ciudadanos y no desde los ratings, de recuperar la palabra y democratizarla, implica repensar los géneros y formatos radiofónicos para que exista una verdadera participación.

\section{Bibliografía}

Gozálvez, V., \& Contreras-Pulido, P. (01 de 01 de 2014). Empoderar a la ciudadanía mediática desde la educomunicaciòn. Comunicar, XXI $\quad$ (42), 129-136. doi:http://dx.doi.org/10.3916/C42-2014-12

Rodríguez Gómez, G., Gil Flores, J., \& García Jiménez, E. (1996). Metodología de la investigación cualitativa. Granda, España: Aljibe. Recuperado el 2017 de 02 de 26

Agency, C. I. (2016). CIA. Recuperado el 16 de 02 de 2017, de https://www.cia.gov/library/publications/the-world-factbook/geos/ec.html

Aguaded, J. (2012). La educomunicaciòn una apuesta de mañana, necesaria para hoy. Aularia revista digital de Educomunicaciòn, 259-261. Obtenido de http://www.aularia.org/ContadorArticulo.php?idart=70

Balcàzar Nava, P., Gonzàlez Arratia Lòpez-Fuentes, N., Gurrola Peña, G. M., \& Moysèn Chimal, A. (2013). Investigación Cualitativa. México: UAEM.

Ballestero, T., Segura, C., Jiménez, A., Ramos, G., Chinchilla, O., Quintero, W.,. . Guichardo, A. (2012). La radio en América Latina y el Caribe, mapa interactivo.

Buendìa Astudillo, A., \& Pino Correa, J. (enero-junio de 2008). Radio local, opinión pública y participación ciudadana. Signo y Pensamiento, XXVII (52), 84-96.

Canclini, N. (2001). Culturas híbridas, estrategias para entrar y salir de la modernidad (Nueva edición ed.). Buenos Aires: Paidós.

Carrillo, A. (9 de diciembre de 2016). Radio educativa y educomunicativa. (M. Santillàn, Entrevistador, \& B. Rodas, Editor) Guayaquil, Guayaas, Ecuador.

Castro Lara, E. (2011). El paradigma latinoamericano de la Educomunicación: El campo para la intervención $\quad$ social. $\quad$ Metacomunicaciòn. Obtenido de https://revistametacomunicacion.files.wordpress.com/2011/10/el-paradigma-latinoamericanode-la-educomunicacic3b3n2.pdf

Garcìa Matilla, A. (2001). Educomunicaciòn en el Siglo XXI. (UNED, Ed.) Obtenido de http://www2.uned.es/ntedu/asignatu/7_Agutin_G_MatillaI1.html\#_ftn1

Geerts, A., \& Van Oeyen, V. (2001). En A. Geerts (Ed.), La radio popular frente al nuevo siglo: estudio de vigencia e incidencia (pág. 283). Quito, Ecuador. Obtenido de www.aler.org.ec

Gehrke, M., Lizarazo, N., Noboa, P., Olmos, D., \& Pieper, O. (2016). Media Development Studies, Panorama de los medios en el Ecuador, Sistema informativo y actores implicados. Germany: Deutsche Welle. 
Gómez, G. O. (2004). La iniciativa de comunicación. Recuperado el 07 de 02 de 2017, de http://www.comminit.com/la/content/la-audienciaci\%C3\%B3n-contempor\%C3\%A1nea-delas-sociedades

Gómez, G. O. (30 de 08 de 2010). Comunicación Estratégica II. Recuperado el 07 de 02 de 2017, de http://comunicacionestrategica2.blogspot.com/2010/08/mass-mediacion-y-audienciacion.html

Hjarvard, S. (enero-junio de 2016). Mediatización: La lógica mediática de las dinámicas cambiantes de la interacción social. (UNR, Ed.) En la trama de la comunicación, 20(1), 235-252. Obtenido de http://www.scielo.org.ar/pdf/trama/v20n1/v20n1a13.pdf

Jacquinot, G. (1999). Educar en los medios de comunicación para favorecer la democracia. Comunicar (13), 25 - 39.

Jordán, R., \& Panchana, A. (2015). Los medios de comunicación en Ecuador.

Kaplun, M. (1998). Una pedagogía de la comunicación. Madrid: Ediciones de la Torre. Recuperado el 07 de 02 de 2017

Morocho, E. (9 de diciembre de 2016). La radio educativa y Comercial. (N. Yuqilema Piedra, Entrevistador)

Navarra, F. J.-L. (03 de 10 de 2004). Ciudadanía, educación y estudios de comunicación. Comunicar (22), 27-30. Recuperado el 21 de 03 de 2017

Pérez, R. (Junio de 2010). Cuando dos son tres. Interacción (51). Recuperado el 19 de 11 de 2016, de http://www.cedal.org.co/index.shtml?apc=h1b1---\&x=596\&cmd[126]=c-1-\%2751\%27

Pérez, R. (Junio de 2010). Cuando dos son tres. (L. F. N., Ed.) Interacción (51).

Ramón, J. (10 de diciembre de 2016). Radio educomunicativa. (A. Ochoa, Entrevistador, \& B. Rodas, Editor) Guayaquil, Ecuador.

Tornero, J. M. (2005). Hacia un nuevo concepto de educación en medios. Comunicar (24), 21-24. Recuperado el 21 de 03 de 2017

UNESCO. (1997). La radio un medio con poder. El correo de la UNESCO, 52.

UNESCO. (2009). La función de los medios de comunicación comunitarios. Obtenido de http://www.unesco.org/new/es/unesco/events/prizes-and-

celebrations/celebrations/international-days/world-press-freedom-day/previous-

celebrations/worldpressfreedomday2009001/themes/the-role-of-community-media/

Villamayor, C., \& Lamas, E. (1998). Gestiòn dela radio comunitariay ciudadana. Fes/Amarc. 